(c) American Dairy Science Association, 2005.

\title{
Fate of Supplementary B-Vitamins in the Gastrointestinal Tract of Dairy Cows*
}

\author{
D. E. Santschi, ${ }^{1}$ R. Berthiaume,${ }^{2}$ J. J. Matte,${ }^{2}$ A. F. Mustafa, ${ }^{1}$ and C. L. Girard ${ }^{2}$ \\ ${ }^{1}$ Department of Animal Science, McGill University, Ste-Anne-de-Bellevue, Quebec, H9X 3V9, Canada \\ ${ }^{2}$ Agriculture and Agri-Food Canada, Dairy and Swine Research and Development Centre, \\ Lennoxville, QC, J1M 1Z3, Canada
}

\begin{abstract}
Four lactating Holstein cows equipped with ruminal, duodenal, and ileal cannulas were used in 2 studies to evaluate the disappearance of supplementary B-vitamins before and from the small intestine. The cows were fed a total mixed ration with chromic oxide in 12 daily meals. Each study consisted of a control (no vitamin supplementation) and a treatment period (with vitamin supplementation). Amounts of vitamins ( $\mathrm{mg} /$ d) supplemented in studies 1 and 2, respectively, were: thiamin: 300 and 10; riboflavin: 1600 and 2.0; niacin: 12,000 and 600 ; vitamin $\mathrm{B}_{6}: 800$ and 34; biotin: 20 and 0.02; folic acid: 2600 and 111 ; vitamin $\mathrm{B}_{12}: 500$ and 0.4 . In study 1 , vitamins were added to the feed $5 \mathrm{~d}$ before and during the 4 -d collection period. In study 2 , vitamins were infused postruminally $1 \mathrm{~d}$ before and during the 4-d collection period. Substantial disappearance before the duodenal cannula was noted in study $1(67.8 \%$ thiamin, $99.3 \%$ riboflavin, $98.5 \%$ nicotinamide, $41.0 \%$ pyridoxine, $45.2 \%$ biotin, $97.0 \%$ folic acid, and $62.9 \%$ vitamin $\mathrm{B}_{12}$ ). Except for nicotinamide and folate, there was almost no disappearance of postruminally infused vitamins before the duodenal cannula (study 2), suggesting extensive ruminal destruction or use. Apparent intestinal absorption values differed greatly among vitamins, but the proportion of vitamins disappearing from the small intestine was not negatively influenced by supplementation. Except for riboflavin and niacin, absolute amounts disappearing from the small intestine were greater during the treatment than the control periods, suggesting that B-vitamin supply in dairy cows is increased by supplementation, although losses in the rumen are extensive.
\end{abstract}

Received December 13, 2004.

Accepted March 13, 2005.

Corresponding author: Christiane L. Girard; e-mail: girardch@ agr.gc.ca.

*Contribution no. 858.
(Key words: dairy cow, B vitamins, ruminal destruction, intestinal absorption)

Abbreviation key: $\mathbf{C O N}=$ control period, $\mathbf{N A}=$ nicotinic acid, NAM = nicotinamide, $\mathbf{P 5 P}=$ pyridoxal-5phosphate, $\mathbf{P A L}=$ pyridoxal, $\mathbf{P A M}=$ pyridoxamine, $\mathbf{P Y R}=$ pyridoxine, $\mathbf{T R T}=$ treatment period.

\section{INTRODUCTION}

Most of the research studying the requirements of dairy cattle for B-vitamins was conducted almost half a century ago. It was concluded then that the mature ruminant animal does not require an exogenous supply of B-vitamins, because its rumen microflora should synthesize enough of these compounds to avoid deficiency. Since then, dairy cows have greatly increased their average milk and milk component yields. It is likely that their B-vitamin requirements increased accordingly and that ruminal synthesis alone may not be sufficient to meet the new needs, as supported by studies reporting beneficial effects of dietary supplementation of thiamin (Shaver and Bal, 2000), niacin (Fronk and Schultz, 1979; Riddell et al., 1981), biotin (Zimmerly and Weiss, 2001), and folic acid (Girard and Matte, 1998). Nevertheless, the exact fate of these vitamins in the digestive tract of ruminants is still unknown. Data are often extrapolated from nonruminant animals, but the precision of such estimates has not been verified.

Zinn et al. (1987) presented 2 studies looking at ruminal destruction and intestinal absorption of most of the B-vitamins in growing steers. According to their results, extensive loss of supplementary vitamins occurs before the small intestine, which complicates supplementation. Intestinal absorption rates reported by Zinn et al. (1987) were similar to those of Miller et al. (1986) estimated with heavier steers and were close to values observed in nonruminant animals. However, the literature still lacks information about the availability of dietary supplements of B-vitamins for dairy cows.

The present experiment was undertaken to evaluate the disappearance of supplementary B-vitamins before and from the small intestine of lactating dairy cows. As extensive ruminal destruction or use was expected, 
the effect of postruminal infusions of vitamins on their availability was also investigated. In addition, estimates of daily amounts of vitamins being synthesized in the rumen of dairy cows were calculated.

\section{MATERIALS AND METHODS}

\section{Animals and Diets}

Four multiparous lactating Holstein cows [DIM: between 29 and 178; milk production during the trial: $27.7 \pm 1.4 \mathrm{~kg} / \mathrm{d}$ (mean $\pm \mathrm{SE}$ )] equipped with cannulas in the rumen, the proximal duodenum $(\sim 30 \mathrm{~cm}$ from the pylorus), and the distal ileum ( $\sim 60 \mathrm{~cm}$ from the ileocecal valve) were used. The experimental procedures of this study were approved by the Institutional Animal Care Committee of the Dairy and Swine Research and Development Center, Lennoxville, QC, and followed the guidelines of the Canadian Council on Animal Care (1993). The cows were fed a TMR containing chromic oxide as digesta passage marker 12 times daily (Table 1). Chromic oxide was included in the protein supplement pellets. Amounts of feeds offered were limited to $95 \%$ of the ad libitum intake measured the week before the beginning of the experiment, to avoid refusals and maintain a similar feed intake between the periods [average DMI during studies 1 and $2: 19.8 \pm 0.5 \mathrm{~kg} / \mathrm{d}$ (mean $\pm \mathrm{SE})]$. The cows were milked twice daily at 0900 and 2100 h. Feed and water intakes, feed refusals (when present), and milk production were recorded daily. Feed samples were taken weekly and frozen at $-20^{\circ} \mathrm{C}$ for later analyses of chemical composition and vitamin concentrations.

\section{Treatments and Collection of Samples}

The experiment was conducted as 2 separate studies. Each study consisted of a control period (CON; no vitamin supplementation) and a treatment period (TRT; with vitamin supplementation). The vitamins provided in the TRT periods were: thiamin (thiamin hydrochloride; Sigma, St. Louis, MO), riboflavin (Sigma), niacin (nicotinamide; Sigma), vitamin $\mathrm{B}_{6}$ (pyridoxine hydrochloride; Sigma), biotin (Sigma), folic acid (pteroylmonoglutamic acid; ICN Biomedicals, Cleveland, $\mathrm{OH}$ ), and vitamin $\mathrm{B}_{12}$ (cyanocobalamin; Hoffmann-LaRoche, Cambridge, Ontario, Canada). Daily amounts of vitamins supplemented in each study are reported in Table 2. The amounts of thiamin, niacin, biotin, folic acid, and vitamin $\mathrm{B}_{12}$ provided in study 1 were based on the literature (Frigg et al., 1993b; Shaver and Bal, 2000; Girard et al., 2001), whereas quantities of riboflavin and vitamin $\mathrm{B}_{6}$ (in the form of pyridoxine) were calculated on a BW basis from Zinn et al. (1987) for a cow weighing $650 \mathrm{~kg}$. In study 2 , levels of vitamins infused
Table 1. Ingredients, chemical composition, and vitamin concentrations of the basal diet.

\begin{tabular}{|c|c|c|}
\hline \multicolumn{3}{|l|}{ Item } \\
\hline $\mathrm{DM}$ & 40.0 & \\
\hline \multicolumn{3}{|l|}{ Ingredients (\%, DM basis) } \\
\hline Grass-legume silage & 43.6 & \\
\hline Corn silage & 14.7 & \\
\hline High moisture corn & 33.6 & \\
\hline Soybean meal & 0.8 & \\
\hline Protein supplement & 4.9 & \\
\hline Corn gluten meal & & 1.1 \\
\hline Extruded soybean & & 1.0 \\
\hline Wheat distillers & & 1.0 \\
\hline Canola meal & & 1.0 \\
\hline Corn distillers & & 0.7 \\
\hline Chromic oxide & & 0.08 \\
\hline Mineral and vitamin premix ${ }^{1}$ & 2.3 & \\
\hline \multicolumn{3}{|c|}{ Chemical composition (\%, DM basis) } \\
\hline $\mathrm{CP}$ & 17.7 & \\
\hline Soluble protein & 7.1 & \\
\hline $\mathrm{ADICP}^{2}$ & 7.4 & \\
\hline $\mathrm{NDICP}^{3}$ & 14.4 & \\
\hline $\mathrm{ADF}$ & 20.0 & \\
\hline $\mathrm{NDF}$ & 28.2 & \\
\hline Nonstructural carbohydrates & 44.3 & \\
\hline Fat & 2.6 & \\
\hline Ash & 7.2 & \\
\hline \multicolumn{3}{|c|}{ B-Vitamin concentrations (ug/g DM) } \\
\hline Thiamin & 2.09 & \\
\hline Riboflavin & 5.18 & \\
\hline Niacin $^{4}$ & 23.80 & \\
\hline Nicotinic acid (NA) & & 23.80 \\
\hline Nicotinamide (NAM) & & 0.00 \\
\hline Vitamin $\mathrm{B}_{6}{ }^{5}$ & 8.50 & \\
\hline Pyridoxamine (PAM) & & 0.64 \\
\hline Pyridoxal (PAL) & & 1.56 \\
\hline Pyridoxine (PYR) & & 6.30 \\
\hline Biotin & 7.04 & \\
\hline Folates & 0.35 & \\
\hline Vitamin $\mathrm{B}_{12}$ & 0.010 & \\
\hline
\end{tabular}

${ }^{1}$ Composition per kg: $95.3 \mathrm{~g} \mathrm{Ca}, 54.7 \mathrm{~g} \mathrm{P}, 34.9 \mathrm{~g} \mathrm{Mg}, 132.6 \mathrm{~g} \mathrm{Na}$, $74.3 \mathrm{~g} \mathrm{Cl}, 14.4 \mathrm{~g} \mathrm{~K}, 20.8 \mathrm{~g} \mathrm{~S}, 2.7 \mathrm{~g} \mathrm{Fe}, 2.1 \mathrm{~g} \mathrm{Mn}, 3.0 \mathrm{~g} \mathrm{Zn}, 499 \mathrm{mg}$ $\mathrm{Cu}, 69 \mathrm{mg} \mathrm{I}, 33 \mathrm{mg} \mathrm{Co}, 17 \mathrm{mg}$ Se, $369500 \mathrm{IU}$ vitamin A, $65130 \mathrm{IU}$ vitamin $\mathrm{D}$, and $1.8 \mathrm{~g}$ of DL-tocopherol acetate.

${ }^{2}$ Acid detergent insoluble CP.

${ }^{3}$ Neutral detergent insoluble CP.

${ }^{4} \mathrm{Sum}$ of the molar concentrations of NA and NAM; expressed as NA-equivalents.

${ }^{5}$ Sum of the molar concentrations of PAM, PAL, and PYR; expressed as PYR-equivalents.

were based on preliminary trials conducted on one dry cow equipped with ruminal, duodenal, and ileal cannulas.

Duodenal and ileal samples (approximately $350 \mathrm{~mL}$ ) were collected twice daily over 4 consecutive days in both the CON and the TRT periods (d 1: 0800 and 1400 h; $d$ 2: 1000 and $1600 \mathrm{~h} ; \mathrm{d}$ 3: 1100 and $1700 \mathrm{~h} ; \mathrm{d}$ 4: 0900 and $1500 \mathrm{~h}$ ). Samples were considered missing if they could not be collected within $45 \mathrm{~min}$ of the target time. Three ileal samples were missing: two in study 1, and one in study 2 . A rest period of $8 \mathrm{~d}$ was allowed between the 2 studies to reduce carryover effects. 
Table 2. Amounts of B-vitamins supplemented in the diet (study 1) or infused postruminally (study 2$)$ (mg/d).

\begin{tabular}{lcc}
\hline Vitamin & $\begin{array}{l}\text { Dietary } \\
\text { supplement } \\
\text { (study 1) }\end{array}$ & $\begin{array}{l}\text { Postruminal } \\
\text { infusion } \\
\text { (study 2) }\end{array}$ \\
\hline Thiamin & 300 & $10 \pm 0.3$ \\
Riboflavin & 1600 & $2.0 \pm 0.04$ \\
Nicotinamide & 12,000 & $1173 \pm 7$ \\
Pyridoxine (vitamin $\mathrm{B}_{6}$ ) & 800 & $34 \pm 2$ \\
Biotin & 20 & $0.02 \pm 0.0005$ \\
Folic acid & 2600 & $111 \pm 5$ \\
Vitamin $\mathrm{B}_{12}$ & 500 & $0.4 \pm 0.01$ \\
\hline
\end{tabular}

${ }^{1}$ The amounts infused are calculated as the infusion rates multiplied by vitamin concentrations in the infused solutions. These variables were measured twice daily during the $5 \mathrm{~d}$ of infusion.

In study 1 , the vitamins were given as dietary supplements. Vitamins were mixed with ground corn and added to the feed at each meal. Supplementation took place $5 \mathrm{~d}$ before and during the $4 \mathrm{~d}$ of collection in the TRT period. Biotin values from one cow were removed due to an error during preparation of the vitamin supplement.

In study 2 , the vitamins were infused postruminally as described by Griinari et al. (1997). For this purpose, the B-vitamins were dissolved in a sufficient amount of water to infuse at a rate of approximately $4 \mathrm{~L} / \mathrm{d}$ [3.79 $\pm 0.03 \mathrm{~L} / \mathrm{d}$ (mean $\pm \mathrm{SE})]$. The rate of infusion was determined by difference in the weight of the vitamin solution remaining to be infused, which was taken twice daily. Infusions lasted $5 \mathrm{~d}$, that is, $1 \mathrm{~d}$ before and during the 4-d collection period of the TRT period.

\section{Laboratory Analyses}

Digesta samples were frozen at $-20^{\circ} \mathrm{C}$ until being freeze-dried and ground through a $1-\mathrm{mm}$ screen. The samples were then composited by day, cow, and collection site. Analyses of B-vitamin and chromic oxide concentrations were performed on the pooled digesta samples and in the feed.

The HPLC system used for the analysis of thiamin, riboflavin, and vitamin $\mathrm{B}_{6}$ consisted of the following components: a solvent delivery (model 110B; Beckman, Fullerton, CA), an autosampler with a $10-\mu \mathrm{L}$ injection loop (model 9300; Varian, Walnut Creek, CA), and a fluorimetric detection system (model LC240; Perkin Elmer, Woodbridge, Ontario, Canada).

Thiamin. Thiamin concentrations were analyzed in duplicate by HPLC according to a method adapted from Botticher and Botticher (1986). A sample of $0.1 \mathrm{~g}$ was mixed with $5 \mathrm{~mL}$ of sulfuric acid $(0.1 M)$ in a $15-\mathrm{mL}$ polypropylene conical tube and was autoclaved for 15 min at $121^{\circ} \mathrm{C}$. After cooling, $0.5 \mathrm{~mL}$ of sodium acetate $(4.5 \mathrm{M}$ ) and $0.25 \mathrm{~mL}$ of Clara-diastase (amylase EC
3.2.1 from Aspergillus oryzae; $50 \mathrm{mg} / \mathrm{mL}$ ) were added. The samples were incubated for $18 \mathrm{~h}$ in a water bath at $45^{\circ} \mathrm{C}$ and then centrifuged at $1784 \times g$ for $10 \mathrm{~min}$ at $4^{\circ} \mathrm{C}$. Immediately after centrifugation, $1 \mathrm{~mL}$ of the supernatant was mixed with $225 \mu \mathrm{L}$ of oxidative solution $(175 \mu \mathrm{L}$ of $\mathrm{NaOH} 50 \%$ and $50 \mu \mathrm{L}$ of potassium ferricyanide 5\% per sample). After 5 min of incubation, approximately $0.25 \mathrm{~g}$ of $\mathrm{NaCl}$ was added to each tube. Following mixing, $2.0 \mathrm{~mL}$ of 2-butanol was added, the samples were agitated for $1 \mathrm{~min}$ and were then injected into the HPLC. Routine HPLC analysis was carried out on a Nucleosil- $\mathrm{NH}_{2}$ column $(250 \mathrm{~mm} \times 4.6 \mathrm{~mm}, 5 \mu$; Varian) preceded by a guard column. The mobile phase was composed of $250 \mathrm{~mL}$ of $\mathrm{KH}_{2} \mathrm{PO}_{4}$ and $750 \mathrm{~mL}$ of acetonitrile at a flow rate of $1.5 \mathrm{~mL} / \mathrm{min}$, with the fluorimetric detection system adjusted to 425 and $370 \mathrm{~nm}$ for emission and excitation, respectively. Recovery rates averaged 95.8 and $106.9 \%$ for the duodenal and ileal samples, respectively. Rates of conversion of thiamin monophosphate and thiamin triphosphate into thiamin were both $100 \%$. Interassay coefficients of variation averaged $12.2 \%$. An intraassay coefficient of variation of less than $10 \%$ was accepted between duplicates.

Riboflavin. Measurements of riboflavin concentrations were done in duplicate according to a method adapted from Giguère et al. (2002). All forms of the vitamin were transformed into riboflavin for analysis. Briefly, $0.2 \mathrm{~g}$ of feed or digesta and $20 \mathrm{~mL}$ of $\mathrm{HCl}(0.1$ $M)$ were combined in $12 \times 75-\mathrm{mm}$ borosilicate tubes and centrifuged for $5 \mathrm{~min}$ at $1784 \times \mathrm{g}$. Five hundred microliters of supernatant was combined with $200 \mu \mathrm{L}$ of $15 \%$ perchloric acid to precipitate protein, and the samples were then boiled for $10 \mathrm{~min}$. Following centrifugation at $1854 \times \mathrm{g}$ for $10 \mathrm{~min}, 400 \mu \mathrm{L}$ of the supernatant was added to $200 \mu \mathrm{L}$ of sodium acetate $(4.0 M)$ and 25 $\mu \mathrm{L}$ of acid phosphatase $2 \%$ [20 mg phosphatase per $\mathrm{mL}$ of ammonium acetate buffer ( $50 \mathrm{~m} M, \mathrm{pH} 4.0)$ ]. Samples were then incubated for $18 \mathrm{~h}$ in a water bath at $37^{\circ} \mathrm{C}$ to convert flavin-adenine dinucleotide into riboflavin. After centrifugation for $10 \mathrm{~min}$ at $1854 \times g$, samples were injected into the HPLC. A Microsorb-MV 100-5 C18 column $(250 \times 4.6 \mathrm{~mm}$; Varian $)$ was used, with a mobile phase composed of $80 \mathrm{~mL}$ of ammonium acetate buffer ( $\mathrm{pH} 4.0$ ), $800 \mathrm{~mL}$ of ultrapure water, and 200 $\mathrm{mL}$ of acetonitrile at a flow rate of $1.0 \mathrm{~mL} / \mathrm{min}$. The fluorimetric detection system was adjusted to 520 and $450 \mathrm{~nm}$ for emission and excitation, respectively. Recovery rates averaged $101.9 \%$ for the duodenal and $94.2 \%$ for the ileal samples. Mean rate of conversion of flavinadenine dinucleotide into riboflavin was $96.2 \%$. The mean interassay variation coefficient was $15.3 \%$. A coefficient of variation of less than $10 \%$ was accepted between duplicates in an assay. 
Niacin. Concentrations of nicotinic acid (NA) and nicotinamide (NAM) were determined in duplicate according to a method adapted from Mawatari et al. (1991), Lahély et al. (1999), and Ndaw et al. (2002). In summary, $0.1 \mathrm{~g}$ of feed or digesta was added to $7 \mathrm{~mL}$ of $\mathrm{HCl}(0.1 M)$ in $15-\mathrm{mL}$ polypropylene conical tubes. All the samples were then autoclaved for $50 \mathrm{~min}$ at $121^{\circ} \mathrm{C}$. After cooling, the tubes were diluted to a final volume of $10 \mathrm{~mL}$ with ultrapure water and were centrifuged for $10 \mathrm{~min}$ at $1854 \times \mathrm{g}$ and $4^{\circ} \mathrm{C}$. Approximately $2 \mathrm{~mL}$ of supernatant was collected, of which $20 \mu \mathrm{L}$ was injected into the HPLC. Samples were run through a Pursuit C18 column ( $150 \mathrm{~mm} \times 4.6 \mathrm{~mm}$ i.d., $5 \mu$; Varian) preceded by a guard column (MetaGuard Pursuit, 4.6 $\mathrm{mm}$ i.d., $5 \mu$; Varian). The postcolumn photochemical reaction was carried out in a polytetrafluoroethylene tube $(10 \mathrm{~m} \times 0.5 \mathrm{~mm}$ i.d. $)$ that was wound around a black light (Black-Ray model XX-20BLB, 300 to $400 \mathrm{~nm}$ with a filter excluding the $254 \mathrm{~nm}$ line, $115 \mathrm{~V}, 60 \mathrm{~Hz}$, 60 A; UVP, Upland, CA). The mobile phase consisted of potassium dihydrogen phosphate $(0.07 M)$, hydrogen peroxide $(0.075 M)$, and copper II sulfate $(5.1 \mu M)$. The flow rate was adjusted to $1.5 \mathrm{~mL} / \mathrm{min}$ and the fluorimetric detector operated at an excitation wavelength of $322 \mathrm{~nm}$ and an emission wavelength of $380 \mathrm{~nm}$. Recovery rates for NA and NAM averaged respectively, 93.9 and $102.7 \%$ for the duodenal samples and 98.4 and $96.7 \%$ for the ileal samples. Interassay coefficients of variation averaged 7.7 and $11.2 \%$ for NA and NAM, respectively.

As reported by Ndaw et al. (2002), hydrolysis of the samples in $\mathrm{HCl}$ led to partial conversion of NAM into NA. This conversion was observed with standard solutions of NAM, but it is not known if it occurred in the same manner and to the same magnitude in samples. Accordingly, no correction was made to adjust the values, which suggests a slight overestimation of NA concentrations coupled with an underestimation of NAM concentrations for the samples, nevertheless, resulting in a correct evaluation of total niacin.

Vitamin $\boldsymbol{B}_{6}$. Vitamin $\mathrm{B}_{6}$ concentrations were determined according to a method adapted from Matte et al. (1997) and Srivastava and Beutler (1973). Samples were analyzed in duplicate for 3 different forms of vitamin $\mathrm{B}_{6}$ simultaneously: pyridoxamine (PAM), pyridoxal (PAL), and pyridoxine (PYR); pyridoxal-5-phosphate (P5P) was converted to PAL for analysis. Briefly, $9 \mathrm{~mL}$ of sulfuric acid $(0.01 \mathrm{M})$ was added to $0.2 \mathrm{~g}$ of sample and autoclaved for $15 \mathrm{~min}$ at $121^{\circ} \mathrm{C}$. After cooling, the sample was diluted to a final volume of $20 \mathrm{~mL}$ with ultrapure water. The samples were then centrifuged for $10 \mathrm{~min}$ at 15,142 $\times \mathrm{g}$. From the supernatant, $1 \mathrm{~mL}$ was incubated with $25 \mu \mathrm{L}$ of acid phosphatase $2 \%$ (phosphatase in ammonium acetate buffer; $50 \mathrm{mM}$,
$\mathrm{pH}$ 4.0) for $18 \mathrm{~h}$ in a water bath at $37^{\circ} \mathrm{C}$ to convert $\mathrm{P} 5 \mathrm{P}$ into PAL. The samples were then centrifuged again 10 $\min$ at $15,142 \times g$ before being injected into the HPLC, using the same column as for riboflavin analyses. The mobile phase used for vitamin $\mathrm{B}_{6}$ consisted of $2.4 \mathrm{~mL}$ of sulfuric acid per $1000 \mathrm{~mL}$ of ultrapure water, and had a flow rate of $1 \mathrm{~mL} / \mathrm{min}$. Emission and excitation wavelengths on the fluorimetric detection system were 290 and $395 \mathrm{~nm}$, respectively. Rates of recovery were (respectively for duodenal and ileal samples): 100.6 and 68.7\% for PAM; 94.8 and $79.6 \%$ for PAL; and 99.1 and $87.3 \%$ for PYR. The composition of the ileal samples (color and viscosity) seemed to interfere with analysis. The lower recovery rates for these vitamins suggest slight underestimation of the values reported for the ileal samples in the present experiment. Average conversion rate from $\mathrm{P} 5 \mathrm{P}$ into $\mathrm{PAL}$ was $86.6 \%$. The lower conversion rate of this vitamin could be due to its high sensitivity to light and other environmental conditions. Interassay coefficients of variation averaged 14.9, 14.5, and $27.1 \%$ for PAM, PAL, and PYR, respectively. Concentrations of some forms of this vitamin were close to the level of detection of the method used. Consequently, a coefficient of variation of $20 \%$ or less was accepted between duplicates in the same assay.

Biotin. Biotin concentrations were quantified in duplicate by ELISA according to an adaptation of the techniques described by Wellenberg and Banks (1993) and Bayer et al. (1990). Coating of a 96 -well plate (flatbottomed immuno plate, Maxisorp; Nalge Nunc International, Rochester, NY) was done by incubating 100 $\mu \mathrm{L}$ of biotin-conjugated antibody (antimouse IgG biotin conjugate, antibody developed in goat; Sigma) in each well for $3 \mathrm{~h}$ at $37^{\circ} \mathrm{C}$. The wells were then rinsed 4 times with $300 \mu \mathrm{L}$ of a washing solution (0.05\%) made of PBS and Tween 80 in the ratio 2:1. Following rinsing, 300 $\mu \mathrm{L}$ of BSA was added and the plate was incubated for $1 \mathrm{~h}$ at $37^{\circ} \mathrm{C}$. The wells were then rinsed again 4 times with the washing solution, and $100 \mu \mathrm{L}$ of avidin solution (per plate: $12.0 \mathrm{~mL}$ of PBS and $40 \mu \mathrm{L}$ of avidin) were added to each well before the final incubation at $23^{\circ} \mathrm{C}$ for $45 \mathrm{~min}$.

Approximately $0.125 \mathrm{~g}$ of sample was dissolved in 25 $\mathrm{mL}$ of ultrapure water. Dried pancreas extract (pancreas acetone powder, bovine; Sigma) was added to the samples. This extract contained biotinidase, the only enzyme known to degrade the bound form of the vitamin biocytin (biotin bound to lysine) (Le Grusse and Watier, 1993) and to consequently release free biotin for analysis. Precisely $1000 \mathrm{mg}$ of dried pancreas extract was added; the tubes were mixed carefully and were then incubated in the ultra-sound bath for $15 \mathrm{~min}$ and in a water bath at $37^{\circ} \mathrm{C}$ for $18 \mathrm{~h}$. Following incubation, samples were autoclaved for $10 \mathrm{~min}$ at $121^{\circ} \mathrm{C}$ to stop 
all enzymatic activity. After cooling, volumes were diluted to $50 \mathrm{~mL}$ with ultrapure water, and tubes were centrifuged for $10 \mathrm{~min}$ at $1538 \times g$ and $4^{\circ} \mathrm{C}$. Samples were diluted 1:70 in PBS to achieve a final dilution of 1:3500. This dilution rate had been previously tested in our laboratory to be optimal regarding viscosity (conferred by the pancreas extract and interfering with the analyses) and vitamin concentration, to get precise and repeatable values. Each plate also had wells containing only pancreas extract (without sample) to quantify the concentration of biotin in the pancreas, which was then subtracted from the final concentration of biotin per gram for each sample.

A volume of $100 \mu \mathrm{L}$ of each diluted sample was put in the wells, and the plate was incubated for $45 \mathrm{~min}$ at $23^{\circ} \mathrm{C}$. The wells were then rinsed 4 times with 300 $\mu \mathrm{L}$ of the washing solution, and $100 \mu \mathrm{L}$ of peroxidase solution was added to each well (per plate: $12.0 \mathrm{~mL}$ of PBS and $4 \mu \mathrm{L}$ of labeled biotinamidocaporyl peroxidase). Samples were incubated again at $23^{\circ} \mathrm{C}$ for 30 min and rinsed 4 times as before. A volume of $100 \mu \mathrm{L}$ of a substrate solution [per plate: $12.25 \mu \mathrm{L}$ of acetate buffer, $200 \mu \mathrm{L}$ of 3,3-5,5 tetramethylbenzidine solution (6 mg per $\mathrm{mL}$ of dimethylsulfoxide), and $50 \mu \mathrm{L}$ peroxide $10 \%$ ] was added to each well, and the plate was protected from light for 15 to $30 \mathrm{~min}$, until the coloration was clearly visible but not saturated. The reaction was then stopped with $50 \mu \mathrm{L}$ of sulfuric acid $(1.8 M)$. The plate was agitated for $8 \mathrm{~s}$ before being read at 450 and $650 \mathrm{~nm}$. After subtraction of the 2 values obtained ( 650 $\mathrm{nm}-450 \mathrm{~nm}$ ), a 4-parameter regression curve was used to quantify the concentrations. Without treatment with pancreas extract, biocytin was not detected by the assay but the rate of conversion of biocytin into biotin following the enzymatic treatment was $91.9 \%$. Less than $8 \%$ of the total biotin found in feed and duodenal samples could be detected when no biotinidase treatment was applied to the samples (unpublished data). Recovery rates were 98.8 and $95.1 \%$ for total biotin in duodenal and ileal samples, respectively. A coefficient of variation of $10 \%$ or less was accepted between samples in a same assay.

Folates. Folate concentrations were measured in duplicate as described by Girard et al. (1994). A sample of $0.1 \mathrm{~g}$ of solid was homogenized in a grinder tube with $8 \mathrm{~mL}$ of McIlvain's buffer (per L of buffer: $28.392 \mathrm{~g}$ of $0.2 \mathrm{M} \mathrm{Na}_{2} \mathrm{HPO}_{4}$ and $0.5 \mathrm{~g}$ of ascorbic acid dissolved in distilled water, $\mathrm{pH}$ adjusted to 4.6 with $1.0 \mathrm{M}$ citric acid, diluted to $1000 \mathrm{~mL}$ with distilled water). The homogenate was then transferred to conical polypropylene tubes and autoclaved for $10 \mathrm{~min}$ at $121^{\circ} \mathrm{C}$. The $\mathrm{pH}$ was adjusted to 7 with $\mathrm{NaOH}(3.3 M)$, and the volume was diluted to $10 \mathrm{~mL}$ with distilled water. The solutions were centrifuged at $1854 \times \mathrm{g}$ for $10 \mathrm{~min}$, and the super- natants were diluted 1:2 with BSA (7\%). Folates were then analyzed by radioassay (Quantaphase Folate, BioRad Laboratories, Mississauga, Ontario, Canada). Recovery rate averaged $104.2 \%$. Interassay coefficients of variation were below $10 \%$.

Vitamin $\boldsymbol{B}_{12}$. Only the biologically active form of vitamin $B_{12}$ (true vitamin $B_{12}$ ) was analyzed in the present experiment. Hydrolysis of $0.1 \mathrm{~g}$ of sample was done using $24 \mathrm{~mL}$ of extractive solution (per L: $13 \mathrm{~g}$ of $\mathrm{Na}_{2} \mathrm{HPO}_{4}, 12 \mathrm{~g}$ of citric acid, and $10 \mathrm{~g}$ of sodium metabisulfite in distilled water). Samples were then autoclaved at $121^{\circ} \mathrm{C}$ for $10 \mathrm{~min}$. After cooling, $\mathrm{NaOH}$ (3.3 $M$ ) was added to bring the $\mathrm{pH}$ to approximately 6.2 to 6.5 , and the final volume was diluted to $30 \mathrm{~mL}$ with distilled water. From that solution, $200 \mu \mathrm{L}$ was used to determine the concentration of the vitamin. Vitamin concentrations were determined using a commercial kit (Quantaphase $\mathrm{B}_{12}$; BioRad Laboratories Ltd.). Rate of recovery in duodenal and ileal digesta samples averaged respectively, 101.3 and $104.3 \%$. Interassay coefficients of variation were always below $10 \%$.

Chromic oxide. Chromic oxide concentrations were determined by atomic absorption as described by Siddons et al. (1985) with air-acetylene being used instead of $\mathrm{N}_{2} \mathrm{O}$-acetylene for better combustion conditions. A coefficient of variation of $2.5 \%$ or less was accepted between duplicates.

\section{Calculations and Statistical Analyses}

Daily values of intestinal flows of vitamins for each cow were averaged over the $4 \mathrm{~d}$ of the same period, and the mean for each animal was used for further calculations.

Apparent daily ruminal synthesis during the CON periods was calculated as the intake of vitamin in the feed subtracted from the duodenal flow and averaged for the 4 cows.

Disappearance before the duodenal cannula during the TRT periods in both studies was calculated individually for each cow, and the mean of the 4 cows was then reported for each vitamin. It was calculated as the amount of vitamins appearing at the duodenum relative to the quantity given:

$$
\begin{gathered}
\text { Disappearance }(\%)= \\
\frac{100 \times([\text { Duo TRT }]-[\text { Duo CON }])}{\text { Amount of vitamin supplemented }(\mathrm{mg} / \mathrm{d})}
\end{gathered}
$$

where [Duo TRT] is the duodenal flow of vitamin during the TRT period (mg/d); and [Duo CON] is the duodenal flow of vitamin during the CON period $(\mathrm{mg} / \mathrm{d})$.

Average apparent intestinal disappearance for the 4 cows was calculated as the amount disappearing be- 
tween the 2 intestinal cannulas compared with the amount arriving at the duodenum, for both the CON and the TRT periods, in studies 1 and 2:

$$
\begin{aligned}
& \text { Intestinal disappearance }(\%)= \\
& \frac{100 \times([\text { Duo }]-[\text { Ile }])}{[\text { Duo }]}
\end{aligned}
$$

where [Duo] is the duodenal flow of vitamin (mg/d); and [Ile] is the ileal flow of vitamin (mg/d).

A paired $t$-test was performed to compare the mean intestinal disappearance rates between the CON and TRT periods of each study, to verify if supplementation of vitamins negatively affected their apparent absorption. Means were assumed to be different from each other at $P \leq 0.05$ and tend to differ at $0.05<P \leq 0.10$.

\section{RESULTS AND DISCUSSION}

Although the design used results in complete confounding between period and treatment, this design was chosen preferentially to a crossover design to overcome the problems related to the major role played by the enterohepatic cycle in the folate and vitamin $\mathrm{B}_{12}$ metabolism, and to the fact that concentrations of those vitamins increased in bile with vitamin intake (Steinberg et al., 1979; Schneider, 1987; Le Grusse and Watier, 1993). To prevent a period effect between the 2 periods of one study, the amount of feed offered to the cows was restricted to $95 \%$ of their ad libitum intake and was maintained throughout the project.

Average duodenal and ileal daily flows of the different vitamins are reported in Table 3. Large variation was noted between animals. However, our data suggest a change in intestinal flows in response to supplementation for most of the vitamins studied, as well as substantial amounts apparently disappearing from the small intestine. Average intestinal flows of vitamins reported in the present experiment are similar to the values presented by Schwab et al. (2004a,b), obtained from lactating dairy cows fed different forage and nonfiber carbohydrate concentrations.

\section{Apparent Ruminal Synthesis}

Average amounts of vitamins being produced daily in the rumen of the 4 cows for studies 1 and 2 are reported in Table 4. Estimates of ruminal synthesis obtained in the present experiment do not account for destruction or use in the rumen, nor for absorption, which could take place through the walls of the 4 stomach compartments or at the level of the duodenum, before the cannula. The values reported probably un- derestimate the net amount of vitamins being produced by ruminal bacteria.

Duodenal flows of most vitamins were higher than intake levels, suggesting that ruminal production was occurring. Vitamin $\mathrm{B}_{12}$, which is synthesized solely by microorganisms and only under adequate cobalt supply (McDowell, 2000), showed the greatest increase in flow relative to the amount consumed daily. Biotin, according to our results, does not seem to be synthesized in the rumen. However, this vitamin might be destroyed or used at the same rate as it is produced, suggesting no apparent synthesis, as reported by Frigg et al. (1993a).

Daily ruminal synthesis of niacin was more than 2.2 $\mathrm{g}$ in the present experiment. Niacin exerts its major functions in its coenzyme forms (NAD and NADP), which are especially important in reactions that provide energy to the animal (McDowell, 2000). Results from the present study indicate that both NA and NAM were synthesized in substantial amounts in the rumen of dairy cattle, which is in opposition to results from Campbell et al. (1994). These authors reported that only NA could be detected in ruminal and duodenal fluids, but they did not measure niacin concentrations in total ruminal or duodenal contents (which also includes feed particles and bacterial cells). It is therefore likely that both forms of niacin were synthesized in the rumen, but that most of NA and all NAM was present within the bacterial cells.

The negative value obtained for PYR is mainly due to the conversion of this form of the vitamin into PAM and PAL. Pyridoxine, the predominant form in plants (McDowell, 2000), represented almost $75 \%$ of total vitamin $B_{6}$ in the feed, whereas it accounted for approximately $20 \%$ of the vitamin at the duodenal level. Accordingly, PAM and PAL (the forms usually found in animal products) represented, respectively, 8 and $18 \%$ in the feed, and increased to proportions around 40 and $35 \%$ of the duodenal flow of vitamin $\mathrm{B}_{6}$ during the control periods. The slightly negative value for total vitamin $\mathrm{B}_{6}$ suggests that no net synthesis of this vitamin occurred, and that the increases in PAM and PAL were solely due to interconversions between the forms of the vitamin. Our results indicate that most of this conversion took place in the rumen, since daily flows of the other forms of vitamin $B_{6}$ were not altered by the postruminal infusion of PYR (study 2).

\section{Disappearance Before the Duodenum}

Study 1. Average rates of disappearance of dietary supplemented vitamins before the small intestine are reported in Table 5. As indicated by these results, substantial proportions of the supplemented vitamins were destroyed or used before the duodenum. Riboflavin, nia- 
Table 3. Intestinal flows of B-vitamins in studies 1 and $2(\mathrm{mg} / \mathrm{d})^{1,2}$

\begin{tabular}{|c|c|c|c|c|}
\hline & \multicolumn{2}{|c|}{ Study 1} & \multicolumn{2}{|c|}{ Study 2} \\
\hline & CON & TRT & $\mathrm{CON}$ & TRT \\
\hline \multicolumn{5}{|l|}{ Thiamin } \\
\hline Duodenal flow & $66 \pm 3$ & $163 \pm 30$ & $68 \pm 7$ & $78 \pm 9$ \\
\hline Ileal flow & $16 \pm 5$ & $85 \pm 27$ & $19 \pm 6$ & $25 \pm 4$ \\
\hline \multicolumn{5}{|l|}{ Riboflavin } \\
\hline Duodenal flow & $361 \pm 29$ & $371 \pm 27$ & $375 \pm 26$ & $380 \pm 24$ \\
\hline Ileal flow & $233 \pm 12$ & $244 \pm 27$ & $239 \pm 27$ & $237 \pm 16$ \\
\hline \multicolumn{5}{|l|}{ Niacin $^{3}$} \\
\hline Duodenal flow & $2777 \pm 416$ & $2724 \pm 365$ & $2578 \pm 249$ & $2946 \pm 279$ \\
\hline Ileal flow & $418 \pm 25$ & $410 \pm 23$ & $416 \pm 78$ & $422 \pm 60$ \\
\hline \multicolumn{5}{|c|}{ Nicotinic acid (NA) } \\
\hline Duodenal flow & $1420 \pm 257$ & $1259 \pm 182$ & $1334 \pm 125$ & $1815 \pm 114$ \\
\hline Ileal flow & $343 \pm 28$ & $324 \pm 25$ & $361 \pm 50$ & $355 \pm 55$ \\
\hline \multicolumn{5}{|c|}{ Nicotinamide (NAM) } \\
\hline Duodenal flow & $1276 \pm 198$ & $1458 \pm 187$ & $1242 \pm 182$ & $1140 \pm 116$ \\
\hline Ileal flow & $77 \pm 12$ & $83 \pm 3$ & $84 \pm 23$ & $64 \pm 17$ \\
\hline \multicolumn{5}{|l|}{ Vitamin $\mathrm{B}_{6}{ }^{4}$} \\
\hline Duodenal flow & $150 \pm 11$ & $656 \pm 73$ & $153 \pm 19$ & $171 \pm 18$ \\
\hline Ileal flow & $47 \pm 6$ & $99 \pm 14$ & $43 \pm 6$ & $46 \pm 4$ \\
\hline \multicolumn{5}{|c|}{ Pyridoxamine (PAM) } \\
\hline Duodenal flow & $66 \pm 6$ & $77 \pm 9$ & $60 \pm 7$ & $62 \pm 6$ \\
\hline Ileal flow & $8 \pm 2$ & $13 \pm 3$ & $6 \pm 1$ & $7 \pm 1$ \\
\hline \multicolumn{5}{|l|}{ Pyridoxal (PAL) } \\
\hline Duodenal flow & $48 \pm 3$ & $70 \pm 9$ & $56 \pm 12$ & $47 \pm 6$ \\
\hline Ileal flow & $22 \pm 2$ & $28 \pm 3$ & $22 \pm 3$ & $19 \pm 1$ \\
\hline \multicolumn{5}{|l|}{ Pyridoxine (PYR) } \\
\hline Duodenal flow & $31 \pm 5$ & $503 \pm 76$ & $26 \pm 3$ & $65 \pm 11$ \\
\hline Ileal flow & $20 \pm 6$ & $60 \pm 8$ & $13 \pm 3$ & $18 \pm 3$ \\
\hline \multicolumn{5}{|l|}{$\operatorname{Biotin}^{5}$} \\
\hline Duodenal flow & $120 \pm 6$ & $136 \pm 9$ & $152 \pm 12$ & $132 \pm 13$ \\
\hline Ileal flow & $90 \pm 8$ & $85 \pm 11$ & $81 \pm 6$ & $83 \pm 7$ \\
\hline \multicolumn{5}{|l|}{ Folates } \\
\hline Duodenal flow & $27 \pm 2$ & $106 \pm 2$ & $28 \pm 2$ & $111 \pm 7$ \\
\hline Ileal flow & $40 \pm 3$ & $102 \pm 16$ & $38 \pm 3$ & $102 \pm 11$ \\
\hline \multicolumn{5}{|l|}{ Vitamin $\mathrm{B}_{12}$} \\
\hline Duodenal flow & $75 \pm 5$ & $261 \pm 38$ & $70 \pm 6$ & $72 \pm 5$ \\
\hline Ileal flow & $67 \pm 2$ & $223 \pm 35$ & $62 \pm 6$ & $59 \pm 4$ \\
\hline
\end{tabular}

${ }^{1}$ Mean \pm SE. CON $=$ No vitamin supplementation; TRT $=$ with vitamin supplementation in feed (study 1) or infused in duodenum (study 2 ).

${ }^{2}$ Mean intake on basal ration (mg/d): thiamin: $41 \pm 1$; riboflavin: $101 \pm 3$; niacin: $465 \pm 16$; NA $465 \pm 16$; NAM 0; vitamin $B_{6}$ : $166 \pm 6$; PAM: $13 \pm$ 0.4; PAL: $30 \pm$; PYR: $123 \pm 4$; biotin: $138 \pm$ 5; folates: $7 \pm 0.2$; vitamin $\mathrm{B}_{12}: 0.2 \pm 0.01$.

${ }^{3}$ Sum of the molar concentrations of NA and NAM; expressed as NA-equivalents.

${ }^{4}$ Sum of the molar concentrations of PAM, PAL, and PYR; expressed as PYR-equivalents.

${ }^{5}$ Means calculated on 3 cows for the TRT period of study 1 .

cin, and folates almost completely disappeared before the duodenal cannula $(99.3,98.5$, and $97.0 \%$, respectively), whereas less than half of the supplemented dose of vitamin $\mathrm{B}_{6}$ and biotin was destroyed or used (41.0 and $45.2 \%$ respectively). Disappearances of thiamin and vitamin $\mathrm{B}_{12}$ were intermediate $(67.8$ and $62.9 \%$, respectively). Zinn et al. (1987) had previously reported extensive disappearance of supplementary B-vitamins. These authors reported similar rates of ruminal disappearance for riboflavin $(98.8 \%)$, niacin $(93.8 \%)$, and folates (97.3\%) than the results presented here. However, they observed lower ruminal disappearance rate for thiamin (47.7\%), and higher values for vitamin $\mathrm{B}_{12}$ $(90 \%)$. In addition, these authors suggested that vita- min $\mathrm{B}_{6}$ and biotin were not destroyed in the rumen (respectively, 101.0 and $132.5 \%$ of the supplementary doses escaping the rumen). The animals used by Zinn et al. (1987) were steer calves with lower intake levels and fed a diet richer in concentrates than the cows used in our experiment, which probably influenced bacterial population as well as transit time, which in turn could affect ruminal use (and synthesis) of B-vitamins. Other authors reporting ruminal disappearance of supplementary B-vitamins obtained values slightly different from ours. Frigg et al. (1993b) noted no significant ruminal degradation of biotin in Brown Swiss heifers, and Smith and Marston (1970) estimated that in sheep, approximately $80 \%$ of oral vitamin $\mathrm{B}_{12}$ disappeared be- 
Table 4. Apparent ruminal synthesis of B-vitamins during the control periods (average of studies 1 and 2).

\begin{tabular}{lcr}
\hline & $\begin{array}{l}\text { Apparent } \\
\text { ruminal } \\
\text { synthesis } \\
(\mathrm{mg} / \mathrm{d})\end{array}$ & $\mathrm{SE}$ \\
Vitamins & 26 & 3 \\
\hline Thiamin & 267 & 17 \\
Riboflavin & 2213 & 224 \\
Niacin & 912 & 132 \\
Nicotinic acid (NA) & 1259 & 125 \\
Nicotinamide (NAM) & -14 & 7 \\
Vitamin B $_{6}^{2}$ & 51 & 4 \\
Pyridoxamine (PAM) & 24 & 6 \\
Pyridoxal (PAL) & -94 & 6 \\
Pyridoxine (PYR) & -1 & 9 \\
Biotin & 21 & 1 \\
Folates & 73 & 4 \\
Vitamin B $_{12}$ & & \\
\hline
\end{tabular}

${ }^{1}$ Sum of the molar concentrations of NA and NAM; expressed as NA-equivalents.

${ }^{2}$ Sum of the molar concentrations of PAM, PAL, and PYR; expressed as PYR-equivalents.

fore the small intestine. These values are closer to those of Zinn et al. (1987) than ours are, but the different methods of analysis used may explain part of the discrepancy between the levels of vitamins detected. Microbiological assays are less specific than the chemical methods used in the present experiment and may not take into consideration the different forms of the vitamins and the analogues that may be present.

In the present experiment, preintestinal disappearance rates could have been slightly overestimated, and apparent ruminal synthesis was probably underestimated, because absorption through the 4 stomach compartments or in the duodenum before the cannula cannot be excluded.

Using isotope labels, Smith and Marston (1970) demonstrated that neither thiamin nor $\mathrm{B}_{12}$ was absorbed in appreciable amounts through the ruminal wall. Similarly, results from Rérat et al. (1958a,b; 1959) indicated that, although the rumen wall is permeable to free vitamins, no significant absorption takes place in normally

Table 5. Disappearance rates of B-vitamins before the duodenal cannula following dietary supplementation in study 1 .

\begin{tabular}{llr}
\hline & $\begin{array}{l}\text { Ruminal } \\
\text { disappearance } \\
(\%)\end{array}$ & SE \\
\hline Vitamins & 67.8 & 8.9 \\
Thiamin & 99.3 & 1.7 \\
Riboflavin & 98.5 & 1.8 \\
Niacin (as nicotinamide) & 41.0 & 8.9 \\
Vitamin $\mathrm{B}_{6}$ (as pyridoxine) & 45.2 & 37.7 \\
Biotin $^{1}$ & 97.0 & 0.5 \\
Folic acid & 62.9 & 7.5 \\
Vitamin $\mathrm{B}_{12}$ & & \\
\hline
\end{tabular}

${ }^{1}$ Mean calculated on 3 cows. fed animals. The lack of absorption in the rumen is likely because most of the vitamins are present in the bacterial fraction of ruminal content, and therefore not available in their free form. However, an accumulation of vitamins in the ruminal wall has been reported, making the vitamins available for later release in the blood or the rumen cavity (Rérat et al., 1958b; Smith and Marston, 1970).

Although probably minimal in the present experiment, absorption through the ruminal wall cannot be totally excluded, because levels of free vitamins were considerably increased during the dietary supplementation period. This is the case mainly for NAM, of which $12 \mathrm{~g}$ was supplemented daily. Erickson et al. (1991) observed that NAM was absorbed in the rumen at a rate of $0.98 \mathrm{~g} / \mathrm{h}$, whereas NA did not seem to be absorbed over a 1-h period. Because almost no niacin escaped the rumen in the present experiment, it may be suggested that the numerous beneficial effects reported for supplementary niacin may be either due to its roles in the rumen, or simply because the supplemented vitamin reaches the circulation through diffusion across the gastrointestinal wall before the duodenal cannula. Rérat et al. (1958b) showed that thiamin, riboflavin, niacin, pantothenic acid, and vitamin $\mathrm{B}_{12}$ could be absorbed through the rumen wall when large quantities of these vitamins are present in their free form. Accordingly, Girard et al. (2001) and Girard and Rémond (2003) noted that although no net positive flows were found under normal conditions, folates, and vitamin $\mathrm{B}_{12}$ were able to reach the blood circulation through the rumen wall of normally fed cows and sheep following an infusion of high doses of these vitamins. However, the efficiency of this process is very low.

Study 2. Study 2 was designed to verify the hypothesis that disappearance of dietary vitamins before the small intestine takes place in the rumen, and that digestion and absorption following the forestomach is similar in ruminant and nonruminant animals. Accordingly, only negligible amounts of infused vitamins were lost before the duodenum in this study, except for niacin and folic acid. Duodenal flows of NAM were not increased following the postruminal infusion of this form of niacin. However, the infusion of NAM resulted in an increase of NA [average increase for the 4 cows (mean $\pm \mathrm{SE}$ ): $481 \pm 100 \mathrm{mg} / \mathrm{d}]$. Conversion of the amide into the acid form has already been reported in extraction methods involving acids (Ndaw et al., 2002). This conversion could also take place in the acidic environment of the abomasum of dairy cows. Accordingly, Campbell et al. (1994) reported increased duodenal NA concentrations for cows supplemented with NAM (12 g/d). However, these authors only considered duodenal fluid, and 
Table 6. Apparent intestinal disappearance during the CON and TRT periods for studies 1 and 2.,

\begin{tabular}{|c|c|c|c|c|c|c|}
\hline \multirow[b]{2}{*}{ Vitamins } & \multicolumn{2}{|c|}{$\begin{array}{c}\text { Study } 1 \\
\text { Intestinal disappearance } \\
(\%)\end{array}$} & \multirow[b]{2}{*}{$P$} & \multicolumn{2}{|c|}{$\begin{array}{c}\text { Study } 2 \\
\text { Intestinal disappearance } \\
(\%)\end{array}$} & \multirow[b]{2}{*}{$P$} \\
\hline & $\mathrm{CON}$ & TRT & & $\mathrm{CON}$ & TRT & \\
\hline Thiamin & $77 \pm 7$ & $55 \pm 13$ & 0.09 & $73 \pm 6$ & $67 \pm 5$ & 0.47 \\
\hline Riboflavin & $35 \pm 3$ & $36 \pm 4$ & 0.88 & $37 \pm 4$ & $37 \pm 4$ & 0.79 \\
\hline Niacin $^{3}$ & $84 \pm 4$ & $84 \pm 2$ & 0.87 & $84 \pm 2$ & $85 \pm 3$ & 0.76 \\
\hline Nicotinic acid (NA) & $73 \pm 6$ & $73 \pm 4$ & 0.99 & $73 \pm 4$ & $80 \pm 4$ & 0.18 \\
\hline Nicotinamide (NAM) & $94 \pm 2$ & $94 \pm 1$ & 0.68 & $94 \pm 1$ & $94 \pm 1$ & 0.63 \\
\hline Vitamin $\mathrm{B}_{6}^{4}$ & $69 \pm 4$ & $85 \pm 2$ & 0.02 & $72 \pm 4$ & $73 \pm 1$ & 0.60 \\
\hline Pyridoxamine (PAM) & $89 \pm 3$ & $83 \pm 2$ & 0.08 & $90 \pm 2$ & $88 \pm 2$ & 0.15 \\
\hline Pyridoxal (PAL) & $55 \pm 5$ & $60 \pm 3$ & 0.46 & $59 \pm 7$ & $57 \pm 4$ & 0.66 \\
\hline Pyridoxine (PYR) & $46 \pm 12$ & $88 \pm 2$ & 0.09 & $50 \pm 14$ & $72 \pm 2$ & 0.23 \\
\hline Biotin $^{5}$ & $28 \pm 9$ & $37 \pm 5$ & 0.38 & $46 \pm 6$ & $36 \pm 6$ & 0.07 \\
\hline Folates & $\mathrm{Neg}^{\overline{6}}$ & $10 \pm 5$ & - & Neg & $16 \pm 5$ & - \\
\hline Vitamin $\mathrm{B}_{12}$ & $11 \pm 4$ & $15 \pm 4$ & 0.40 & $11 \pm 2$ & $16 \pm 7$ & 0.55 \\
\hline
\end{tabular}

therefore did not account for niacin, which could have been found in the solid fraction of intestinal content.

Between 18 and 36\% (mean \pm SE: $25 \pm 4$ ) of the infused dose of folic acid was not recovered at the duodenum. Folate absorption takes place in the proximal duodenum (Le Grusse and Watier, 1993; McDowell, 2000), and it is likely that some absorption may have occurred before the duodenal cannula. This would imply that the rate of ruminal disappearance of folic acid was overestimated, and that a proportion of the supplemented vitamin was not used or destroyed in the rumen, but rather absorbed before the duodenal cannula. These results further suggest that ruminal synthesis of folates may be underestimated, because although the vitamin is bound to other material in the rumen, it is released upon passage through the abomasum, and could therefore be available for absorption early in the small intestine.

Although duodenal flows of most vitamins were increased by the postruminal infusions, the levels of riboflavin, biotin, and vitamin $\mathrm{B}_{12}$ infused were too small to induce a change in concentrations in the duodenal flows of these vitamins.

\section{Apparent Intestinal Disappearance Rate}

Average apparent intestinal disappearance rates for the 4 cows are reported in Table 6. Apparent absorption of thiamin and PAM in study 1 tended to be reduced $(P \leq 0.09)$ during the treatment periods. For all other vitamins, the treatment had either a positive or no significant effect on apparent intestinal absorption.

Thiamin. Average intestinal disappearance rates obtained for thiamin in the present experiment are similar to those reported by Zinn et al. (1987) and Miller et al. (1986), which were both approximately 75\%. Although the proportion of this vitamin disappearing from the small intestine seemed to be reduced during the TRT periods, especially in study 1 , absolute amounts being absorbed by the cow were higher than in the CON periods.

Riboflavin. Because less than $1 \%$ of the supplemented dose of riboflavin reached the small intestine, absolute amounts of this vitamin disappearing between the 2 intestinal cannulas were not increased in the TRT period in study 1 . Moreover, amounts infused in study 2 were not sufficient to increase duodenal flows of riboflavin. Previous studies reported slightly lower intestinal disappearance rates than the values obtained in the present study, ranging from 25 to $28 \%$ of the amount of vitamin arriving at the duodenum (Miller et al., 1986; Zinn et al., 1987). However, these estimations were calculated from studies with steers with lower intake levels than the animals used in the present experiment.

Niacin. Apparent intestinal absorption of NA and NAM were 73 and $94 \%$, respectively, and averaged $84 \%$ of duodenal flows of total niacin. These values for total niacin agree well with those reported by Zinn et al. (1987) and Miller et al. (1986) for beef cattle (79 and 70\% of duodenal levels, respectively). In study 1, apparent 
absorption rates for the CON and TRT periods were identical due to the substantial disappearance of this vitamin before the small intestine. The slightly increased absorption rate observed for NA in the treatment period of study $2(80 \%)$ can be attributed to the conversion of NAM into NA following postruminal infusion, as discussed earlier.

Vitamin $\boldsymbol{B}_{6}$. The slightly reduced apparent absorption rate for PAM did not affect total vitamin $\mathrm{B}_{6}$ absorption, which was significantly increased by the dietary supplementation in study $1(P=0.02)$. Absorption of vitamin $\mathrm{B}_{6}$ mainly occurs in one of the dephosphorylated forms; PAM, PAL, and PYR having equal activities in animals and being interconvertible in the tissues (McDowell, 2000). This suggests that the sum of the forms of vitamin $B_{6}$ being taken up by the intestine is more important for the dairy cow than the proportions of the different forms. Intestinal disappearance rates for vitamin $B_{6}$ are close to the estimation of $79 \%$ obtained with growing steers (Zinn et al., 1987).

Biotin. Biotin apparent absorption rates during the CON periods are slightly lower than those reported by Frigg et al. (1993a), who estimated that 50 to $60 \%$ of dietary biotin was taken up by the small intestine. However, these authors mentioned that their analysis may not be specific, and could therefore have included biotin analogues. Concerning biotin in the TRT period of study 2 , a greater quantity of this vitamin should have been infused to the animals to clearly see the effects of the postruminal infusion. However, our results clearly showed that absorption of this vitamin was occurring in the small intestine of dairy cows, unlike what was suggested for steers by Miller et al. (1986). The intestinal synthesis reported by these authors is probably due to the method of analysis used. In the upper digestive tract, most of biotin is bound to proteins, and only a small proportion is in the free form. Proteins are hydrolyzed under the action of proteases and acid in the stomach (or abomasum), and biotin is then released in the form of biocytin, which consists of the vitamin bound to lysine. Normal stomach proteases cannot degrade biocytin. This biotin-lysine bond can only be degraded by a very specific enzyme (biotinidase), which is found in the pancreatic secretions and brush-border membrane, releasing biotin in its free form (Le Grusse and Watier, 1993). Miller et al. (1986) reported no biotinidase treatment of their samples and therefore probably only analyzed free biotin, which resulted in a significant underestimation of the duodenal levels of this vitamin. Due to this underestimation of the duodenal flows of biotin, their results suggested that synthesis of this vitamin was occurring in the small intestine. Similar results had been observed in our laboratory before the use of dried pancreas extract containing biotinidase for the extraction of duodenal samples: biotin concentrations in duodenal samples were lower than in ileal samples, suggesting intestinal synthesis. With the addition of pancreas extract, duodenal levels of biotin increased several fold, but no effect was noted on ileal samples (unpublished results), revealing that most of duodenal biotin was in the form of biocytin whereas ileal biotin was mainly free vitamin. In fact, under the action of endogenous biotinidase in the small intestine, most biotin present in the ileal samples had been converted to free biotin, and could therefore be measured. Analysis of total biotin therefore revealed that absorption rather than synthesis was occurring in the small intestine, as for the other B-vitamins.

Folates. Results from the present experiment suggest that supplementary folates are extensively destroyed or used before they reach the small intestine (study 1) and that some absorption could occur before the duodenal cannula (study 2). In addition, folic acid absorption during the control periods was negative, with concentrations being higher at the ileal than the duodenal level. Intestinal absorption of folic acid has been reported to take place in the proximal duodenum and jejunum (Le Grusse and Watier, 1993; McDowell, 2000). Girard et al. (2001) reported rapid appearance of folates in the portal blood following ingestion of 2.6 $\mathrm{g}$ of folic acid. In their study, $108.7 \mathrm{mg}$ of folates reached the portal blood within $6 \mathrm{~h}$ after supplementation. This quantity represented $98 \%$ of the total amount of folates being absorbed in $24 \mathrm{~h}$. In addition, these authors noted that folates could be measured in the portal circulation as soon as 30 min after ingestion of a dietary supplement. From our results, approximately 10 to $16 \%$ of supplemented folic acid reaching the duodenum was absorbed between the 2 cannulas for the TRT periods. This value, relatively small compared with apparent absorption rates of most of the other vitamins, is probably underestimated, because compounds recycled through the enterohepatic cycle are released between the 2 cannulas, therefore increasing ileal concentrations. Folic acid is known to be extensively recycled through this cycle. Following absorption early in the intestine and liver uptake, methylated folates are rapidly excreted into bile, whereas nonmethylated forms are either methylated and added to the bile or included in the hepatic pool. Bile folates are then reabsorbed in the small intestine and available for distribution to the liver or the tissues (Steinberg et al., 1979; Steinberg, 1984; Le Grusse and Watier, 1993). Using labeled folates, Steinberg et al. (1979) demonstrated that approximately $30 \%$ was taken up by tissues and then returned to the liver for remethylation and recirculation through the bile and small intestine, proving the importance of 
the enterohepatic cycle even once folate has reached the tissues.

Vitamin $\boldsymbol{B}_{12}$. At normal physiological doses, vitamin $\mathrm{B}_{12}$ is absorbed through an extremely specific mechanism in the distal portion of the ileum. If very high doses of this vitamin are provided to the animal, approximately $1 \%$ can be absorbed by passive diffusion along the whole length of the small intestine (Le Grusse and Watier, 1993). In sheep, Smith and Marston (1970) reported that approximately $5 \%$ of ruminally produced $\mathrm{B}_{12}$ was absorbed in the small intestine, whereas Sutton and Elliot (1972) found that between 1 and 35\% of duodenal $\mathrm{B}_{12}$ disappeared between the 2 intestinal cannulas. These authors also suggested that considerable amounts of analogs could be absorbed. In the present experiment, analogs were not measured, and true vitamin $\mathrm{B}_{12}$ absorption rates were $11 \%$ during the $\mathrm{CON}$ periods and 15 to $16 \%$ during the TRT periods. These values are lower than the ones reported by Zinn et al. (1987), which averaged 48\%. Here again, the differences in the animals and methods of analysis used may explain the discrepancy between our results and the literature.

\section{CONCLUSION}

Results from the present studies indicate that some dietary supplemented B-vitamins are extensively destroyed or used before the small intestine. Postruminal infusions proved that most of this disappearance was occurring in the rumen, except for niacin and folic acid. A considerable proportion of folates seemed to be absorbed in the proximal duodenum before the cannula, whereas it appears that niacin was converted to other forms or apparently absorbed through the walls of the gastrointestinal tract. Although net values of ruminal use and intestinal absorption of B-vitamins could not be obtained from the present studies, supplementation clearly lead to an increased supply of vitamins at the duodenal level and to greater amounts apparently disappearing from the small intestine, except for riboflavin and niacin. The results obtained in the present experiment are essential for further studies looking at the effects of B-vitamin supplementation on production or metabolic parameters in dairy cows.

\section{ACKNOWLEDGMENTS}

The authors thank Chrystiane Plante and Véronique Roy for technical support; Yvan Chouinard for his help with postruminal infusion and the material so kindly offered; François Dehours, Denis Thibeault, and Richard Lanctôt for animal care; and Steve Méthot for statistical advice. These studies were financially supported by Balchem Encapsulates, New Hampton, NY.

\section{REFERENCES}

Bayer, E. A., H. Ben-Hur, and M. Wilchek. 1990. Colorimetric enzyme assays for avidin and biotin. Methods Enzymol. 184:217-223.

Botticher, B., and D. Botticher. 1986. Simple rapid determination of thiamin by a HPLC method in foods, body fluids, urine and faeces. Int. J. Vitam. Nutr. Res. 56:155-159.

Campbell, J. M., M. R. Murphy, R. A. Christensen, and T. R. Overton. 1994. Kinetics of niacin supplements in lactating dairy cows. J. Dairy Sci. 77:566-575.

Canadian Council on Animal Care. 1993. Guide to the care and use of experimental animals, 2nd ed. Vol. 1. E. D. Rolfert, B. M. Cross, and A. A. McWilliam, ed. Canadian Council on Animal Care. Ottawa, Ontario, Canada.

Erickson, P. S., M. R. Murphy, C. S. McSweeney, and A. M. Trusk. 1991. Niacin absorption from the rumen. J. Dairy Sci. 74:3492-3495.

Frigg, M., D. Hartmann, and O. C. Straub. 1993a. Biotin kinetics in serum of cattle after intravenous and oral dosing. Int. J. Vitam. Nutr. Res. 63:36-40.

Frigg, M., O. C. Straub, and D. Hartmann. 1993b. The bioavailability of supplemental biotin in cattle. Int. J. Vitam. Nutr. Res. 63:122-128.

Fronk, T. J., and L. H. Schultz. 1979. Oral nicotinic acid as a treatment for ketosis. J. Dairy Sci. 62:1804-1807.

Giguère, A., C. L. Girard, and J. J. Matte. 2002. Erythrocyte glutathione reductase activity and riboflavin nutritional status in earlyweaned piglets. Int. J. Vitam. Nutr. Res. 72:383-387.

Girard, C. L., J. Chiquette, and J. J. Matte. 1994. Concentrations of folates in ruminal content of steers: Responses to a dietary supplement of folic acid in relation with the nature of the diet. J. Anim. Sci. 72:1023-1028.

Girard, C. L., H. Lapierre, A. Desrochers, C. Benchaar, J. J. Matte, and D. Rémond. 2001. Net flux of folates and vitamin $B_{12}$ through the gastrointestinal tract and the liver of lactating dairy cows. Br. J. Nutr. 86:707-715.

Girard, C. L., and J. J. Matte. 1998. Dietary supplements of folic acid during lactation: Effects on the performance of dairy cows. J. Dairy Sci. 81:1412-1419.

Girard, C. L., and D. Rémond. 2003. Net flux of folates and vitamin B12 through the gastrointestinal tract of sheep. Can. J. Anim. Sci. 83:273-278.

Griinari, J. M., M. A. McGuire, D. A. Dwyer, D. E. Bauman, and D. L. Palmquist. 1997. Role of insulin in the regulation of milk fat synthesis in dairy cows. J. Dairy Sci. 80:1076-1084.

Lahély, S., M. Bergaentzlé, and C. Hasselmann. 1999. Fluorimetric determination of niacin in foods by high-performance liquid chromatography with post column derivatization. Food Chem. 65:129-133.

Le Grusse, J., and B. Watier. 1993. Les vitamines. Données biochimiques, nutritionnelles et cliniques. Centre d'études et d'information sur les vitamines, Neuilly-Sur-Seine, France.

Matte, J. J., A. A. Ponter, and B. Sève. 1997. Effects of chronic parental pyridoxine and acute enteric tryptophan on pyridoxine status, glycemia and insulinemia stimulated by enteric glucose in weanling piglets. Can. J. Anim. Sci. 77:663-668.

Mawatari, K., F. Iinuma, and M. Watanabe. 1991. Determination of nicotinic acid and nicotinamide in human serum by high-performance liquid chromatography with postcolumn ultraviolet-irradiation and fluorescence detection. Anal. Sci. 7:733-736.

McDowell, L. R. 2000. Vitamins in animal and human nutrition. Iowa State University Press, Ames.

Miller, B. L., J. C. Meiske, and R. D. Goodrich. 1986. Effects of grain source and concentrate level on B-vitamin production and absorption in steers. J. Anim. Sci. 62:473-483.

Ndaw, S., M. Bergaentzlé, D. Adoué-Werner, and C. Hasselmann. 2002. Enzymatic extraction procedure for the liquid chromatographic determination of niacin in foodstuffs. Food Chem. 78:129-134.

Rérat, A., O. Champigny, and R. Jacquot. 1959. Modalités de l'absorption vitaminique chez les ruminants: Forme et disponibilité des 
vitamines B du bol alimentaire aux différents niveaux digestifs. C. R. Acad. Sci. (Paris) 249:1274-1276.

Rérat, A., H. Le Bars, and J. Molle. 1958a. Utilisation d'une méthode de perfusion pour la mise en évidence de l'absorption des vitamines B chez le mouton normalement alimenté. C. R. Acad. Sci. (Paris) 246:1920-1922.

Rérat, A., J. Molle, and H. Le Bars. 1958b. Mise en évidence chez le mouton de la perméabilité du rumen aux vitamines B et conditions de leur absorption à ce niveau. C. R. Acad. Sci. (Paris) 246:251-254.

Riddell, D. O., E. E. Bartley, and A. D. Dayton. 1981. Effect of nicotinic acid on microbial protein synthesis in vitro and on dairy cattle growth and milk production. J. Dairy Sci. 64:782-791.

Schneider, Z. 1987. The occurrence and distribution of corrinoids In Comprehensive B12. Chemistry, Biochemistry, Nutrition, Ecology, Medicine. Z. Schneider, and A. Stroinski., ed. Walter de Gryter, Berlin, Germany.

Schwab, E. C., C. G. Schwab, C. L. Girard, R. D. Shaver, D. E. Putnam, and N. L. Whitehouse. 2004a. Effects of dietary forage and nonfiber carbohydrate concentrations on apparent B-vitamin synthesis in dairy cows. J. Dairy Sci. 87(Suppl. 1):339. (Abstr.)

Schwab, E. C., C. G. Schwab, C. L. Girard, R. D. Shaver, D. E. Putnam, and N. L. Whitehouse. 2004b. Effects of dietary forage and nonfiber carbohydrate concentrations on B-vitamin intake and duodenal flow in dairy cows. J. Dairy Sci. 87(Suppl. 1):305.(Abstr.)
Shaver, R. D., and M. A. Bal. 2000. Effect of dietary thiamin supplementation on milk production by dairy cows. J. Dairy Sci. 83:2335-2340.

Siddons, R. C., J. Paradine, D. E. Beever, and P. R. Cornell. 1985. Ytterbium acetate as a particulate-phase digesta-flow marker. Br. J. Nutr. 54:509-519.

Smith, R. M., and H. R. Marston. 1970. Production, absorption, distribution and excretion of vitamin B12 in sheep. Br. J. Nutr. 24:857-877.

Srivastava, S. K., and E. Beutler. 1973. A new fluorimetric method for the determination of pyridoxal 5-phosphate. Biochim. Biophys. Acta 304:765-773.

Steinberg, S. E. 1984. Mechanisms of folate homeostasis. Am. J. Physiol. 246:G319-G324.

Steinberg, S. E., C. L. Campbell, and R. S. Hillman. 1979. Kinetics of the normal folate enterohepatic cycle. J. Clin. Invest. 64:83-88.

Sutton, A. L., and J. M. Elliot. 1972. Effect of ratio of roughage to concentrate and level of feed intake on ovine ruminal vitamin $\mathrm{B}_{12}$ production. J. Nutr. 102:1341-1346.

Wellenberg, G. J., and J. N. Banks. 1993. Enzyme-linked sorbent assay to quantify D-biotin in blood. J. Sci. Food Agric. 63:1-5.

Zimmerly, C. A., and W. P. Weiss. 2001. Effects of supplemental dietary biotin on performance of Holstein cows during early lactation. J. Dairy Sci. 84:498-506.

Zinn, R. A., F. N. Owens, R. L. Stuart, J. R. Dunbar, and B. B. Norman. 1987. B-vitamin supplementation of diets for feedlot calves. J. Anim. Sci. 65:267-277. 